\title{
Article
}

\section{A look at S\&T Awareness - Enhancements in India}

\section{Chandra Mohan Nautiyal}

Basing mainly on author's direct involvement in some science communication efforts in India, and other reports, this contribution depicts and analyses the present science communication/ popularization scenario in India. It tries to dispel a myth that rural people don't require or don't crave for $S \& T$ information. It discusses need for science and technology communication, sustaining curiosity and creating role models. Citing cases of some natural, 'unnatural' and organized events, it recounts how $S \& T$ popularization efforts have fared during the past decade and a half. It's made possible using print, $A V$ and interactive media which, at times, require lot of financial inputs. However, this contribution shows that a number of natural and other phenomena can be used to convince people about power of $S \& T$ and in molding their attitude. The cases cited may be from India, but, with a little variation, are true for most of the developing and under-developed societies.

\section{Introduction}

Considering that nearly half of the Indian population is engaged in agriculture but contributes only about one fifth to the GDP, indicates a malaise and calls for more scientific and methodical approach in the farming sector. A change is needed not only in the information base but also the attitude. Therefore, there is a need to examine the role of Science and Technology (S\&T) in their lives and ways to improve the level. Also, the nature and quantum of the required knowledge of S\&T which may be termed essential need a thought.

There have been efforts at all levels in India to enhance this level by organizing a multitude of programmes like awareness seminars, exhibitions, distribution of printed material, use of various other media- all requiring lot of financial inputs but the fact is that nature itself offers a number of phenomena that can be used to convince people about power of S\&T. In the recent past, these efforts have had perceptible influence on the behaviour in the society, and new formats and forms for communication of S\&T continue to be developed. These are accompanied by exploring more and more opportunities to talk about science. Besides, understanding the natural forces is the first step towards exploiting them. The technology, when following this science, helps us to use them for the benefit of humankind. The spread of the knowledge of science and technology is, therefore, important.

Media can play an important role in this. Media and Technology have an interdependent relationship also. Every time there has been an advance in related technology, media has taken new stride. Inventions of the printing press, offset printing, computer, DTP, telephone, teleprinter, internet/ e-mail on one hand, and radio, television on the other, are some examples. Similarly, science and technology also need media to spread their reach. The reach of media into Indian villages is limited as yet, but is now increasing.

\section{Need for S\&T awareness in rural context}

Those with science background may take it for granted that science is essential for society but as stated by Waldegrave, "some see science, and the method of science, as systematically destructive of everything which makes life worth living" [1]. In Peter Day's opinion, '....as many citizens as possible, should comprehend the nature of scientific argument and enquire- what could be called the process of science'[2]. Carl Sagan's saying that 'it is suicidal to create a society dependent upon S\&T in which hardly anybody knows about S\&T', was indeed a timely warning [3].

In today's world, everyone requires a minimum level of science knowledge, even to lead a healthy and happy life. This is apart from acquiring ability to handle gadgets comfortably. But the question of scientific temperament (also enshrined in constitutions of some countries including India's) is even more 
important. For society, in general, attitude is more important than acquiring scientific information. While the information part is more concerned with the material side directly, the former is more concerned with how people react to situations even the social ones. Hence S\&T communication should be taken in a wider sense here and includes interactions.

The life styles, level of essential facilities and educational levels in the rural and urban areas are quite different, especially in the developing countries. In a multifarious society like India's, Mahatma Gandhi's advice to 'think about the poorest of the poor", would be a good guiding mark. Therefore, science communication for the rural folk using media should also be a priority. Numerically, India is dominated by the rural people. But what the media is providing and what the villages need, don't seem to be in perfect match at present. Print media, radio and TV do carry matter on agriculture but, in my belief, there is a fallacy regarding the rural people's need. No doubt, being of direct use, matter on agriculture would immediately interest them, but it's not that rural people are interested only in them.

Curiosity is a basic trait of human nature. If the rural people experience anything new, they also get curious. Be it a comet in the sky, experience of a tremor in the night, a new flower, a new weed or the sky with a strange hue. They want to know the reason even without a background in Astronomy, Earth Science, Botany, Agricultural Science or Physics. If an unschooled young child with no formal education can evince curiosity (in fact, some would say, schooling might have worked against it!), an 'uneducated' villager too can. Lack of 'curiosity' is a main basis for belief in 'superstition'. Curiosity leads to keen observation and questioning. Curiosity ensures that one tries to go to the bottom of the matter rather than being convinced by the simpler dogmatic explanation offered by others. This may mean one will not accept some super natural power as the cause behind a phenomenon but some physical cause, and so on.

To sustain this element of curiosity is a key to evolve a progressive and creative society, immaterial of whether it's rural or urban. Thus many of the exhibitions, lectures etc. considered useless for the rural people are not really useless. Such exposure not only educates people, more importantly, it expands their horizon and is a myopic and blinkered view to consider the rural folks' interest to be limited to only agriculture. Early exposure to trends of modern research will lead to entry of more people from rural areas into research. It will be useful for the society to have people from rural background in the mainstream S\&T research, who'd contribute to research and development with rural needs in mind. Therefore, early exposure of the rural people to modern discoveries and inventions is all the more critical. This may also encourage literacy which, in turn, may help in improving scientific temperament, though the relationship is complex. This is where media and popularization agencies can play a great role. Of course, while communicating for the rural people, one should make efforts to use language, style, similes and metaphors from the rural context. But the subject matters in S\&T are should not be treated to be completely exclusive between rural and urban people.

\section{What draws people to $\mathrm{S} \& \mathrm{~T}$ information and what has been served by media}

The basic factors responsible for attracting a common person to read, hear or watch S\&T information may be: link to one's interest and natural curiosity. It may appear a bit circular as even sustaining curiosity is a feature of a thinking society. Lack of this is a basic factor behind superstitions and faith in the 'super natural'. The relation of the $\mathrm{S} \& \mathrm{~T}$ with life is important. This is reflected in concern for health, diseases and disasters. The relation with economy, quality of life, anxiousness about the future, emotions, relationships and the like, will decide if $\mathrm{S} \& \mathrm{~T}$ communication will appeal to them. The $\mathrm{S} \& \mathrm{~T}$ popularisation efforts that ignore these basic points are unlikely to succeed.

The degree of success may be debated but there have been many health- care campaigns in India which were effective, be it polio drops, iodized salt, AIDS awareness or immunisation. They all cashed on the emotional aspect of attachment to one's kin. Such campaigns are all, in a way, part of communicating science for welfare. However, science communication is a much wider subject and not limited to educating about material benefits, products for comforts, or material for physical well- being alone. People easily get attracted to the information of immediate and direct use. The real challenge at present for the science communicator lies in addressing the other aspect viz. informational and attitudinal. Helping people in keeping abreast with the latest in science and molding their attitude to be scientific are also welfare measures to improve the intellectual health.

Climate- issues like global warming and ozone depletion have been there in the Indian media constantly. Apart from these evergreen environmental issues, several other issues have been in news such 
as health and Information Technology, the latter usually from the angle of utility. In Indian context, the other prominent $\mathrm{S} \& \mathrm{~T}$ - related issues that figured prominently during the past one and a half decade included alignment of planets, AIDS, ancient Indian civilization, cloning, dinosaurs, disasters like plague, Tsunami, Hurricane, landslides and earthquakes, Lord Ganesha's statue 'drinking' milk, Mars- invasion by Spirit and Opportunity, nuclear and space programme successes, origin of man and life, science trains (exhibition on wheels), search for life and other planets, Total Solar Eclipses, and Venus Transit. However, in some prominent papers, the major science and technology news from abroad appears only on the international page. In other words, wider issues in science emanating from abroad are not considered to be of general readers' interest.

The science coverage in newspapers is still largely event- based rather than being scientific contentbased. In India, the national level Children's Science Congress has been one event that has excited and interested the local media and the common man alike. However, somehow, usually they were only covered in the local editions of newspapers though in plenty. This was despite the fact that several times none other than the President of India inaugurated them. Similar is the case with Indian Science Congress, which is usually inaugurated by the Prime Minister of India. There are many other mega hard science events, national/ international conferences that have been going virtually unnoticed by the national media. It may also be attributed to the incremental nature of progress reported in conferences which is too abstract as such but that's where a reporter's skill matters who can put it in perspective. The S\&T coverage of about 1 to 2 percent in most newspaper can hardly be termed satisfactory [4].

\section{The status of $S \& T$ communication efforts and approaches to enhance it}

Even if we leave aside the matter of being updated on the contemporary scientific issues, it's of concern that a common man continues to be surprisingly ignorant of own surrounding and of the basic useful scientific facts of life related to hygiene and health. This is despite the appreciable marathon movements like 'Jathas' and Year of Scientific Awareness-2004 in India. One still finds water- wells without shades and washing of clothes close to un- walled wells. We still hear of prayers being offered rather than vaccination or medicine in case of infectious and other diseases especially in rural areas. Despite a growing involvement of scientists in science communication, availability of better funding for such efforts, events like Science Congress keeping room for it under the section 'Science for School Children' [5], and many renowned scientists treating the speaking about and on science with respect [5],[6], the situation may not be yet termed satisfactory.

In the last few years, direct interaction (like Face- to- Face) has gained popularity and is accepted as a popular mode of science communication. It has become a regular feature during the national level and many district- or state- level Children Science Congress programmes held annually in India where some of the best known and senior most scientists such as the heads of the departments of atomic energy, space, S\&T and others have interacted with the students. The field-based programmes (street plays, puppet shows), blending art and science, have also come up as popular alternative modes of science communication. Given the power conditions in the rural areas, radio may be more relevant there than TV. The fresh advent of Frequency Modulated (FM) transmission in India is a welcome step. It should help to enhance the reach of audio medium especially as even some schools have started their own transmissions.

However, science writing still leaves much to be desired. Internet has been a great boon but has its pitfalls too, especially because of want of authentication. No one can deny that net has been instrumental in making media free in certain sense. But, with information abundant at fingertips, there is also the fear of mis- information being free. There is already fear of information substituting for understanding as cautioned by Prof. Yash Pal [7]. Therefore, more scientists taking to science- writing would be desirable. However, the scientists continue to be in fear of inaccurate reporting while interacting with media, and prefer the peer review and publication to be a more respectable and safer channel. On the other hand, media complains of non- cooperation from the scientists. Rapid growth in S\&T is another important development making the bridging difficult. These considerations necessitate bringing the scientists and the communicators together [8].

It has been stated elsewhere [9] that scientists prefer to let their work speak and usually avoid media. It's like the Indian saints, as evidenced in great scriptures with authors unknown. A reason was also cited why great scientists should also be talked about in addition to their work. There is need for idolising 
scientists. The society follows role models, be it cricketers, politicians or artistes. These days, the media plays a critical role in creating role models. It's necessary to project (deserving) scientists, international or otherwise, to show that society wants them. However, it will be damaging to be confined to the foreign scientists alone, or to only those decorated by the advanced countries. This is because people from the developing or under developed countries wouldn't easily relate to the heroes from advanced places. Models who belong to the same place, give the people a feeling of self respect. Social similarity with the role model reassures people that they can emulate the models. The debates about genetic superiority are not new and a country's own models give more confidence to people. Every society should also find and project its own role models. Even in villages or small towns, there are people who develop indigenous tools and aides for agriculture. There are mechanics in small towns who have taken the "jugad" technology to useful heights. 'Jugad', in local parlance, refers to the local indigenous methods of somehow managing things creatively, be it fixing motorbike, pump, gadget or developing simple substitutes. This projection will be useful to the society by encouraging of fulfilling local needs. The Indian Science Congress did indeed take an initiative in this direction by inviting such inventers and arranging their interaction during its annual meets.

If we look at accounts of the early twentieth century in India and the renaissance in Europe during 14th to 17 th century, both of which saw an emergence of so many creative people, we can appreciate that it's not the material returns alone that attract a potential practitioner to a profession. Many of them died paupers but they commended respect from the society [10]. The role models in the society are followed and, therefore, it will help to put up scientists as role models even in an age of increasing consumerism. Otherwise, soon a situation may arise when there will be only outstanding sales personnel but no inventers or creators to provide products.

Science communication and popularization has been picking up momentum again. In addition to increasing number of planetariums, science museums/ centres and science cities, there is enough activity in media. The National Council for Science Museums, Kolkata has been particularly active in creating science museums, science cities and also publishes a newsletter. There are several other magazines in other Indian languages doing reasonably well. The science fiction scenario in Assamese, Bangala, Hindi, Kannada, Malayalam, Marathi, Punjabi and Tamil languages is reviewed in the Proceedings for the Eighth National Conference on Science Fiction Writers [11]. A Hindi science magazine Vigyan has been appearing uninterrupted since 1913. As early as 1924, Rahul Sanskrityayan had published a science fiction in Hindi by name Baaiisavee Sadee (Twenty- second Century). This was the first Hindi novel of this genre but the initiative was not followed. Over the past few years, we have seen resurgence of science fiction in India. This is reflected in the beginning of a quarterly science fiction magazine Vigyan Katha (the first in Hindi) by Bharatiya Vigyan Katha Lekhak Samiti, Faizabad (India), and has completed 6 years. There has been more frequent publication of science fiction in 'Science Reporter' and 'Vigyan Pragati'. These two magazines, published by National Institute for Science Communication and Information Resources (NISCAIR) of Council of Scientific and Industrial Research (CSIR), are among the magazines with highest circulation among the popular science magazines in India. On smaller but effective scale, magazines are appearing in several regional languages too that include science- based material especially for children. Further, several science fiction compilations, a book on Hindi science fiction [12] and a book of 70 poems on science by name Vigyananjali in Hindi [13] also appeared.

Several professional societies, for example National Academy of Sciences, Geological Society of India and Indian Academy of Sciences, now hold special science programmes for the young and also publish books/ magazines for them. The Indian National Science Academy and RVPSP have instituted awards for science popularization. Several ministries promote popular science books in Hindi and confer prizes. During the period of consideration, Vigyan Prasar has been established as an autonomous national institution by Department of Science and Technology.

Indian Science Fiction Writers' Association was founded in Vellore (Tamilnadu) in 1999. Now, for several years, Science Fiction Writers' Conference is being organized with the eighth one having been held in December- 2007 at Puducherry, India. Another conference was organised by Indian Science Writers' Association and RVPSP/ NCSTC (DST) in February, 2008 at Dehradun (Uttaranchal) on genres for communicating science including science fiction. Creative groups dealing with science communication are also becoming visible on net. There is now an active internet forum on Indian science fiction (in.groups.yahoo.com/group/indiansciencefiction/) for over an year. The forum even conducted a novel experiment of having a science fiction written jointly by 6 writers on internet during 2007 . 
While several books/ stories from classic literature of several Indian languages, especially of Hindi and Bangala, have been turned into films, hardly any Indian movie qualifies to be a real Sci- Fi. The first Indian movie (in Hindi) which had some element of Sci-Fi in it was Wahan ke Log (people from there) and included visitors from Mars in its story. It was made in 1967 by Nisar Ahmad Ansari with a good star cast but the film sank. Naturally, then there was a lull. After more than 3 decades came Koi Mil Gaya (a main stream Hindi block- buster) which talked of attempts to communicate with ET and visit of a solar energy- dependent creatures from outside the earth. In between, there had been several television serials but no films. However, things seem to be changing now with about 6 films on floor, all claimed to be science fiction [14]. These are main stream movies with one of them having the highest budget (US \$ 25 million) to date for a Hindi movie. However, it is pre- mature to say whether these are going to be real science fiction, science fantasy or just fantasy with gizmos.

\section{Efforts in science popularisation}

In the past two decades, efforts for science popularization have picked up. These include well funded programmes of a number of governmental agencies and involvement of many non- governmental organization in the efforts.

\subsection{Organised events}

In India, a number of governmental agencies like National Council for S\&T Communication (NCSTC/ RVPSP), National Institute for Science Communication and Information Resources (NISCAIR), National Council for Science Museum (NCSM) and Vigyan Prasar, many voluntary organisations and many individuals have contributed to the science communication efforts by organizing a multitude of programmes including lectures, science film shows and holding exhibitions. These included even exhibitions on wheels using buses and in some even trains. The overwhelming response to Vigyan Rail, which was started in 2004 (science exhibition carried aboard a travelling train), was also a success of a novelty in presentation [15]. It was later followed by the Science Express for exhibits through collaboration between RVPSP and Max Planck Society, Germany during 2008. It also involved Vikram Sarabhai Community Science Centre, Ahmedabad for coordination. The National Children's Science Congress is a joint effort of NCSTC- Network and National Council for S\&T Communication (NCSTC/ RVPSP). It has been able to reach millions of students, teachers and parents in India since its inception in 1993. Under this, children carry out science- based projects on several sub- themes under a main theme usually valid for 2 years. The children, selected out of more than 100 thousand students every year reach the national meet through a multi- tier selection process. The years 2004 and 2005 were celebrated as year of Scientific Awareness and of Physics respectively in India. India is also a part of international programmes such as celebration of the Year of Planet Earth and is celebrating it during 2007- 2009. A number of S\&T Councils and voluntary organizations in different states have also been promoting science popularization all over India.

As for the audio/ visual media, there are slots for science in national and regional radio and TV channels but some of them are shrinking due to increasing advertising to earn revenue. Still several popular science programmes have been made for radio and television and had good listener-/viewer- ship. Some foreign channels available in India, are doing a marvelous job in information dissemination on science, nature, and technology, and are popular. Many of them are dubbed in Hindi. The RVPSP (NCSTC) has also been conducting training workshops for science writing/ journalism in collaboration with various universities, institutions and NGO's. At times, the government- governed (though an autonomous board now) radio also organizes workshops for its staff on popularizing science. Indian Space Research Organisation launched 'Edusat' in 2004. Jointly with several other agencies, they started beaming science programmes through this satellite to 20 states in India in the first phase itself.

However, curiosity is not limited to the formally educated only. Author's first-hand experience during various science communication programmes, for instance, during an S\&T exhibition in a village (Bahadurpur- Jais in district Raebereli, Uttar Pradesh) in February 2006, also revealed that that rural people are inquisitive naturally. There were children coming to the exhibition on crutches, children with ties and proper uniform but also those who were barefoot. Women with veils or faces covered came in 
groups. People from all religions and varied social and educational strata thronged the pavilion of exhibits, asked questions and got into animated discussions. That inauguration of the exhibition was attended by the Union Minister for S\&T and the local Member of Parliament, may have added to the initial draw. But this continued for 5 days, with ever increasing response, even though it was not an exhibition of fancy gadgets, or agricultural tools alone, speaks a lot.

\subsection{The natural events as tools to enhance science awareness and temperament}

No doubt that there are hurdles caused by market forces. But the sustained efforts have usually borne fruit as far getting people interested in science is concerned. The difference in the response of people caused by the positive media impact were clearly visible in the overwhelming response to the Total Solar Eclipse (TSE)- 1995. This was in stark contrast with the deserted roads in 1980 during another TSE. It certainly added to the appeal of the telecast that show was joined in by some well known scientists who were also renowned science communicators. Author's own experience while in Iradatganj (Allahabad), UP for live commentary for national television channel on the Total Solar Eclipse was an eye-opener. People, young and old, flocked from rural areas to the place where the crew camped. Not only this, on the previous night, over 600 children had gathered (missing on their fun of Deewali festival) to talk to scientists and listen to the lectures. During the eclipse, they observed it using filters and projecting through telescopes. They were still there to hear the speakers again after the telecast was over in the morning. So it may not be proper to question the scientific curiosity among the rural people. Another show when media played a great role was the Venus- Transit across the Sun in 2004. It was there on all channels of audio, AV and print media and attracted a very large number of people in many cities all over India, wherever telescopes were arranged to view the event and media covered it very well.

Such successes were a result of efforts of a number of governmental and non- governmental agencies, many scientists and the sustained publicity by print and electronic media. But to be realistic, we can't forget that the market forces too were also quite visible. However, these events wouldn't have been lapped up the way it happened, but for the revenue potential. During the telecast, there was an advertisement of shoes on the screen when eclipse was nearing totality, or there have been advertisements appearing when the ball knocks off bails during a cricket match. So the issue is not of science being picked up and deliberately ignored. The most popular game in India, Cricket, suffers the same fatedespite being a long time favourite of the media too!

There are reasons for the low coverage in Indian media of some events of scientific interest. Some events covered poorly in Indian media included the Cassini spacecraft's Saturn- visit and the Huygens Probe's descent into Titan's (Saturn's satellite) clouds as well as NASA's deep Impact hitting the Tempel- 1 comet with about $400 \mathrm{Kg}$ - heavy- impactor. These could have been covered in more details. Things would have been better covered and watched if the event had been visible from India at some convenient time either on net, television or through available instruments and also through freer availability of the internet.

Natural events like eclipse and planet- transit can be and have been used to educate people and also mold their attitude. Apart from informing people about the scientific facts at such times, one should use it to generate faith in people for predictive and logical power of science. This has indeed been done to some extent in case of solar eclipse and Venus - transit. The disasters of Katrina and Rita Hurricanes in coastal areas of USA were tragic. However, the opportunity could have also been used to tell people about these strange meteorological phenomena.

It may be said that these days, people don't feel so much constrained by the superstitious belief, and curiosity overcomes religious reservations. It happened in the case of Solar Eclipse, which is traditionally considered inauspicious to watch in a major section of Indian society. A word of caution is needed for the less rationalist societies, though even in a relatively rationalist society, so often customs without scientific or rational base are followed for social or sentimental reasons rather than rational. It's essential to learn where to draw a line while castigating common practices. It is also important to distinguish between the culture, harmless customs, religion and the superstitions that can harm. This requires maturity and sensitivity. It is not necessary to trample on toes or cause hurt that may be counterproductive. 


\subsection{The 'unnatural' events}

At times, one finds some impossible claims in media regarding scientific achievement. They are not always product of media alone but some times results of publicity- seeking people. Therefore, to have the claims examined by talking to (other) experts, at least in a preliminary manner, is morally binding on the journalist. Unfortunately, it doesn't always happen. The new claims, even when genuine, are very often contested by peers. But by talking to them all, the journalist does get a better perspective.

At times, supernatural or strange events are reported which provide stories for sensational news. One such incident was reported during July, 2002 from Biswan which is a tehsil in Sitapur district in central Uttar Pradesh (India). The problem, as we learnt from a message from the administrative authorities, was report of sighting of some 'creature' by residents of Biswan. There had already been reporting in the news papers. This creature was termed 'muhnochwa' by the local people, literally meaning face- scratcher. It had thrown the normal life out of gear, spread panic and had led to law and order problem there and some other places too. The people are basically in agriculture or small trades. Educational facilities are up to 12 th standard. There is a sugar factory and some Government officers too but, by and large, the culture is of a small town where word spreads by mouth and people have faith in superstitions.

This study is unorthodox in several ways. It was neither an experiment carried out, and result reported, nor was a field observation such as of a geologist who can describe things comparing with some standard. The term 'observation' would be a misnomer for the statements of people as these descriptions are provided by them and not by us, and we had no way of authenticating or verifying them except for some questioning and trying to look for some visual signs in support. The descriptions are somewhat awkward to describe but it has been done trying to maintain as much fidelity as possible.

The biggest problem was getting at true observations without which science- part can't begin. Here psychological and medical tests should come before the physical or chemical sciences. Physics-wise, many of the observation are possible but not probable. If one tried to build a comprehensive model taking all the observations as true, a somewhat funny and contrived, though by no means impossible, picture could be arrived at.

Most of the people were very clear that this was no supernatural happening. The descriptions of objects also varied. In fact, many of them seemed to be sold to the idea that this was some remote- controlled device. Some whispered about the Middle- East (Asian) connection being common, and therefore of easy accessibility of electronic gadgets in the area. They said light spot moved in sky horizontally, became still at some point and then descended at would- be- victim's house. The reported duration of flight (tens of seconds) rules out meteor. However, usually people overestimate the meteor's flight duration also. But the period of June and July was early for the meteor showers. However, it can be matched with the behaviour of a gas-balloon (even cranes from the nearby wetlands) with some light source (candlestick, bulb and cell?) tied or inside it.

The electric currents just below the surface due to improper earth- connection of electric poles during extremely dry soil conditions may sometimes lead to discharges in atmosphere termed ball lightning [16]. The observed colour (orangish, yellowish) is also said to have been reported in literature. BallLightening is a real atmospheric electrical phenomenon but it's not capable of producing all the reported effects (e.g. scratches; feeling of heavy weight). Also, it's doubtful if the charge within the cloud is enough to cause the reported burns and shock.

Some claimed to have seen cats, one a dog, and in another case a 3 feet high 'floating doll'- like object. The descriptions of the creature varied widely. It would be impossible to reconcile all these observations. Some visual observations may have been partly true, but the identification incorrect. Reported time of some moving lights matched the flight timings. In principle, a 'floating doll' could have been plasmoid. But, in this case, there were no rains and no lightening during that period. So there was no chance of lightning causing heating and subsequent evaporation of ground- silica, followed by reactions leading to a cloud of burning silicon compounds in air, as was suggested by Abrahamson and Dinnis [17].

Some people mentioned shadows. In one place, even an insect had been held responsible. One or two persons described metallic feel. Surprisingly, most of them denied having touched or felt the object which clung to them. They said it weighed heavily $(20-50 \mathrm{~kg})$ on their abdomen or mounted their shoulder! It could have as well been momentum rather than weight, if at all there was some physical object. Many of those, claiming to have been injured, reported burning on scratches/ spots and also weakness. Some said to have experienced shock, when they were touched by the object. However, most 
of them had never experienced electric shock before. To have remote controlled things for light display is alright, but to maneuver things inside houses requires too high a sophistication. Navigation in the dark would demand gadgets like infrared camera/ radar, and transmitter fitted on the object feeding back images to the controller who'd control movements with precision of centimeters- again through electromagnetic signals or an intelligent navigation system attached to the 'creature'. However, not more than 2 or 3 cases of shock were reported to occur the same night and there are some cases when no shock occurred. Cloud of the said dimension (less than a meter) in air is unlikely to have enough charge to cause shock of reported degree. Simplicity of high capacity condenser-set-up tied to some animal is another possibility. It can be done very quickly, easily and almost anywhere. All the cases in the same night are in vicinity. The above is certainly a possible scenario but whether it is probable is difficult to say.

Another reported incident involved clawing by the 'muhnochwa' (in guise of a black dog) past mid night when the 'victim' slept at the terrace along with many others. The 'victim' showed fresh bruises on his upper arms in the morning. There were 2 sets of marks. The marks were 15 in number, each about 3 inches long. There were two sets of bruises and they criss- crossed. According to the 'victim', the 'muhnochwa', which looked like a dog, clawed once. If it's true, the marks couldn't be converging, nor could they exceed the number of claws on 2 front legs of a dog. They could not be criss- crossing either. All these observations were openly stated by the author before all those present.

One of the residents said that he saw a light source in the sky, coming from far and descending over him. Then it started moving up from his feet to head. Then it started dancing on his head. When asked, he emphatically said that he saw it even after it moved above his eye level and when it was dancing on his head! Questioning on it led to realization by those around him that something was wrong about the description! In addition, the way questions were posed to, and answered by the villagers ('victims'), it made clear to everyone else present why the event was imaginary.

The technological difficulties, the limitations imposed by Physics- principles, the self-contradictions in statements and ground realities were patiently made clear to people, even without terming anybody a liar or using technical jargon. Some of the 15 persons, who were approached, may have genuinely believed what they told, but hundreds of others who heard the conversation went back convinced about the reality. The net result was that not only solution to the problem of law and order got solved, but also the demonstration of the power of scientific approach and logic.

Any doubts about the phenomena being unreal were laid to rest as not a single such incident was reported after the visit. The possibility can't be ruled out that at least some were lured into falsifying events or into completely concocting stories in a hope of compensation by the government. Another possible motive could have been drawing attention to the serious electricity supply situation. Several people said that the problem wouldn't be serious, only if power supply were less erratic. The situation, including the local political grouping, indicated that there may have been a human factor and planning involved.

Such 'unnatural' events, tackled with basic logic and scientific thinking, without using equipment, is yet another approach for science communication. The opportunity so offered in the society was used not only to explain the basic principles (energy, electricity, remote control etc.) but also analyzing things logically. Media is often accused of sensationalizing things. It'd be difficult to totally agree or disagree. One can't deny that it may pay, at least in the short term. In 1835, an American paper, The Sun, published from New York sold more copies than ever when it printed an incorrect news item about weird life- forms having been found by African astronomers on Moon [18]. The race to be the first and the fastest takes the toll some times. However, it is not that science alone suffers from such happenings. There are reports of more serious consequences in the society from similar mis- endeavours. We have been hearing about persecution by media even before the prosecution, leading to tragic loss of lives. But it has not been missed by the media itself [19].

\section{Conclusions}

India has seen considerable progress in science communication in the past 15 years. There has been an emergence of organizations as well as individuals. Good budget for science popularization programmes, wider coverage, more incentives and also from just one Kalinga Award for Indian science popularisers till eighties to a tally of 4 now speaks for it. But there is still a lot more to be achieved in quality and quantity. This, combined with the increasing pace of in- pour of information, necessitates bringing 
scientists and communicator/ media people together more frequently and relating them to the societal issues. The common platform has been sometimes tried to creative output such as in making of radioserials like Manav ka Vikas (Evolution of Man), and Dharti Meri Dharti (My Earth). But making them popular poses a dilemma. In an age when marketing forces are dominating, utmost care will have to be taken. On one hand, they have to be considered appropriate tools for selling science but, on the other, one has to take care that the main objective doesn't become secondary. To enhance the reach, adopting more media and more formats is also desired. Considering the low cost, portability and consequent possible penetration of radio, it can be termed to be under- utilized at present. With the viability of FM transmission being more down to earth, and liberal attitude of the government, even some schools in India have started their own broadcasting. But it is still far from really becoming a community radio. More approaches and varied formats will automatically lead to wider audience.

To blame the media or their commercial interests alone for not covering more science wouldn't be fair as the media professionals are also products of this society as are scientists and science activists, including science communicators. They all succumb to emotions and commercial/ professional interest. They also have their attitudes shaped by societal values and experiences (which, ideally, should have been the other way round!). This is not with reference to the scientific information- base but the scientific temperament. During author's experience in investigating Muhnochwa (face- scratcher) menace, the attitude of the media was found transformed and pleasantly positive at the end. After being convinced by the response to the adopted interactive approach, which showed that there was nothing like a facescratcher in reality, the media completely curbed the tendency to sensationalise.

We advocate science- popularization. We also mean to advocate investing considerable manpower and material into it for the development of the society as a whole, including the rural populace. Therefore, objective impact- assessment of the science communication efforts should also be treated seriously. It may be worth considering trying to evolve some quantifying parameters. A better interaction between scientists and communicators is desired and the scientists should also take more responsibility for communicating science and promoting scientific temperament.

It's beneficial to organize programmes for science awareness though it may be constrained by resources, particularly in the case of developing countries. But the nature and even our society, present to us a range of phenomena to explore and understand. They all can be utilized as effective instruments to promote science as well as scientific culture and temperament. The interest of the rural population should not considered limited to agricultural implements. The most important thing in carrying on this process is to sustain and encourage the spirit of enquiry in one and all, and communication agencies can play a very critical role in inculcating this culture.

\section{Acknowledgement}

The opinion expressed in the paper is author's individual opinion and doesn't necessarily represent that of his organization or of those in whose association the science popularization work was done. I'd like to express my thanks to All India Radio, Lucknow and New Delhi; District Science Club, Lucknow; Doordarshan, Lucknow and New Delhi; Local administration of Biswan; RVPSP (DST), New Delhi; VICAS, Allahabad; Vigyan Parishad, Prayag; Vigyan Prasar, Noida; and many friends whose association and support allowed me to accomplish much of what formed base of this work. I also thank Director, BSIP for the support during preparation of this paper and also the permission to communicate the same. The anonymous referee helped through critical comments and I owe thanks for that.

\section{References}

[1] P. Day, Creating and communicating science: "the experience of the royal institution, Current Science 67 (1994) 434.

[2] W. Waldegrave, To communicate across disciplines, Interdisciplinary Science Reviews 19 (1994) 117.

[3] C. Sagan, quoted in SIPIscope 16 (1988) 16, as communicated personally by Dr. Terry Sejnowski.

[4] K. Meenu, Coverage of $S \& T$ in national and regional newspapers: a comparative study, Indian Journal of Science Communication 4 (2005) 7. 
[5] J.V. Vaishampayan and C.M. Nautiyal eds., Report and abstracts of projects for science for school children during Indian science congress (2002).

[6] C.M. Nautiyal (compiler), Beyond the rainbow: the colours of science-Compilation of popular lectures delivered by CNR Rao, R.A. Mashelkar and M. Vijayan eds. (2006).

[7] Y. Pal, Reinventing Education for an Exclusive World, UGC Golden Jubilee Lecture at Mahatma Gandhi University, Kottayam on 26.11.2003, printed in NCSC-2003 Souvenir, S. Hariprasad and CM Nautiyal eds., NCSTC- Network (2003).

[8] C.M. Nautiyal, An idea for a workshop, interfacing scientists, communicators and social scientists, Netletter (Sep. 2003), NCSTC- Network, New Delhi (2003).

[9] C.M. Nautiyal, Science Communication: Quo Vadis?, Indian Media Studies Journal 1, No. 1, Satish Serial Publishing House (2006).

[10] R.A. Ocshe, Before the gates of excellence: determinants of creative genius, Cambridge University Press, Cambridge U.K. (1990).

[11] Proceedings of the Eighth National Conference for Science Fiction Writers at Aurangabad (11- 12 November, 2006) by Marathi Vidnyan Parishad, Aurangabad (2006) 100 pages.

[12] M.M. Gore and A. Mishra, Vigyan katha ka Safar, Manjuli Prakashan, New Delhi (2000).

[13] S.G. Misra and D. Mani eds., Vigyananjalee, Vigyan Parishad, Prayag, Allahabad (1996).

[14] M. Sinha, Bollywood Goes Sci-Fi, The Times of India (Lucknow), 30 March (2008) 15.

[15] B.S. Padmanabhan, Vigyan Rail- Science Exhibition on Wheels, Vigyan Prasar, New Delhi (2006).

[16] R. Arora, Ball lightning without lightning, Proceedings of the 8th International Symposium on Ball Lightning (ISBL04), held at National Central University, Chung-li, Taiwan from 3rd-6th August, 2004 (2006) 11.

[17] J. Abrahamson and J. Dinnis, Phenomenon of Ball Lightening, Nature 403 (2000) 519.

[18] T. Jones, Science in the bear-pit, New Scientist, 7th October (1989) 70.

[19] V. Nanda, Will media draw a line please? The Pioneer (Lucknow Edition), 23rd October (2005) page 13.

\section{Author}

Scientist-in- Charge, Radiocarbon Lab., BSIP, Lucknow (India). MSc Physics (IIT, Roorkee) and doctoral, postdoctoral work at PRL, Ahmedabad. As hobby, pursues science popularisation (print/ radio/ television/ interactive). Lectures on science and its communication. Has been convener of India- wide science popularization efforts, a network of 70 organisations and recognized for research and science popularization by several organizations. On several committees of UP and Uttaranchal S\&T Councils. Fellow, NCSTC- Network; Geological Soc. India; Executive Member, Vigyan Parishad.

Website: http://www.geocities.com/cmnautiyal/cmnautiyal.html [http://www.geocities.com]. E-mail: cmnautiyal@yahoo.co.uk. 